\title{
Changing trends in genital cancer
}

\author{
Abha Singh, Avinashi Kujur* \\ Department of Obstetrics and Gynecology, Pandit Jawahar Lal Nehru Memorial Medical College, Raipur, \\ Chhattisgarh, India \\ Received: 31 January 2017 \\ Accepted: 06 February 2017 \\ *Correspondence: \\ Dr Avinashi Kujur, \\ E-mail: avinashikujur@gmail.com \\ Copyright: (C) the author(s), publisher and licensee Medip Academy. This is an open-access article distributed under \\ the terms of the Creative Commons Attribution Non-Commercial License, which permits unrestricted non-commercial \\ use, distribution, and reproduction in any medium, provided the original work is properly cited.
}

\begin{abstract}
Background: Globally, cancers in all forms are causing about $12 \%$ of all deaths. In developed countries cancer is the second leading cause of death accounting for $21 \%$ of mortality by other causes and in developing countries it ranks third, accounting for $9.5 \%$ of all deaths. The objective was to find the incidence of genital malignancy and any change in the trend at Pandit Jawahar Lal Nehru Memorial Medical College, Raipur, Chhattisgarh, India.

Methods: This was a cross-sectional, retrospective, observational study conducted in Dr. BRAM Hospital, Department of Obstetrics and Gynecology from 2000 to 2015. We analyzed data for demographic profile, type of the genital carcinoma and the stages in which they reported and observed any changing trends.

Results: Over 15 years the contribution of genital cancer remained almost stable at $2.78 \%$ in 2000 to $2.48 \%$ in 2015 . $85 \%$ women belonged to rural residence, $75 \%$ were educated up to high school level and $76 \%$ women were from low socioeconomic status. Maximum prevalence of genital cancer is $65.90 \%$ falls in $45-60$ years age group. Young age at first sexual activity, low education, parity $>4$ were found to be associated risk factors. Most significant changing trend was that the incidence of cancer cervix decreased by $11 \%$. There was a shift from stage III to stage II at the time of reporting. The cancer endometrium emerged as new site for genital cancer with increased incidence.

Conclusions: Cervical cancers are the most common cause of mortality but it is a preventable disease. Its decreasing trend and shift to early stage diagnosis is a positive beginning.
\end{abstract}

Keywords: Cancer cervix, Cancer endometrium, Genital cancer, Risk factors

\section{INTRODUCTION}

Globally, cancers in all forms are causing about $12 \%$ of all deaths. In developed countries cancer is the second leading cause of death accounting for $21 \%$ of mortality by other causes and in developing countries it ranks third, accounting for $9.5 \%$ of all deaths. ${ }^{1}$

According to the latest world cancer report from the world health organization (WHO), more women in India are being newly diagnosed with cancer annually. As against 4.77 lakhs men, 5.37 lakhs women were diagnosed with cancer in India in 2012.
In terms of cancer deaths, the mortality rate among men and women in India is almost the same. While 3.56 lakhs men died of cancer in 2012 in India, the corresponding number for women was 3.26 lakhs. One in every 10 Indians runs the risk of getting cancer before 75 years of age, while seven in every 100 runs the risk of dying from cancer before their $75^{\text {th }}$ birthday. ${ }^{2}$ The global community can expect an increase of incidence of about $1 \%$ each year, more in India. In 2030 , incidence may increase to $20-26$ million with around 13-17 million mortality. Cancer cases doubled globally between 1975 and 2000, will double again by 2020 and triple by 2030. The rapid increase in the 
global cancer burden represents a real challenge for health systems worldwide. ${ }^{3}$

With the aim of finding the incidence of malignancy, any change in trend at our Institute this study was undertaken.

\section{METHODS}

This was a cross-sectional, retrospective, observational study conducted in Dr. BRAM Hospital in Department of Obstetrics and Gynecology.

We collected the data of all women who were diagnosed and treated for any malignancy and registered for the same from 2000 to 2015 .

\section{Inclusion criteria}

All women with genital cancer were included. We analyzed for demographic profile, type of the carcinoma and the stages in which they reported and observed any changing trend over past 15 years.

\section{RESULTS}

On analysing the data we realized that over the span of 15 years the contribution of genital cancer remained almost stable $2.78 \%$ in 2000 to $2.48 \%$ in 2015 however number of women with genital cancer have been increased from 132 to 857 in our institute.

$85 \%$ women were of rural residence, $75 \%$ were educated up to high school level and $76 \%$ women belong to low socioeconomic status.

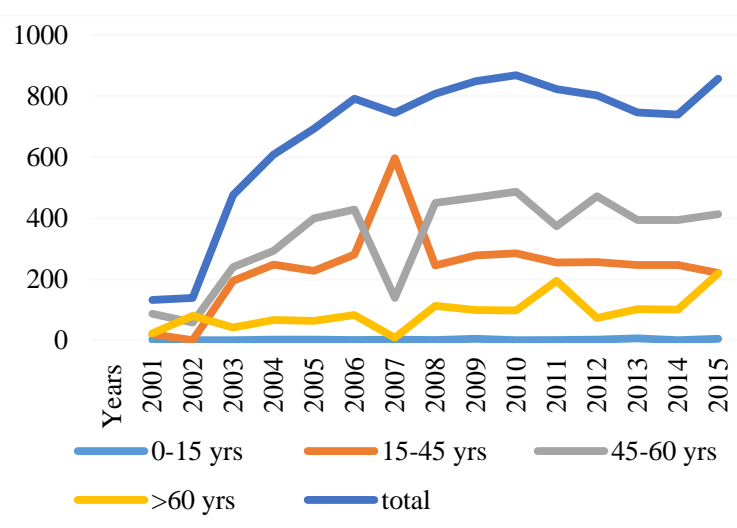

Figure 1: Distribution of genital cancer according to age.

Analysis of age wise distribution of cancer (Figure 1) reveals that in year 2000 maximum prevalence of genital cancer $(87,65.90 \%)$ was in $45-60$ years age group. This trend was maintained over the years till 2015 with a decline of about $15 \%(413,48.19 \%)$. In year 2007 there was a transient shift to $40-45$ years age group with rise in prevalence $(597,80.13 \%)$, followed by a fall by $50 \%$.

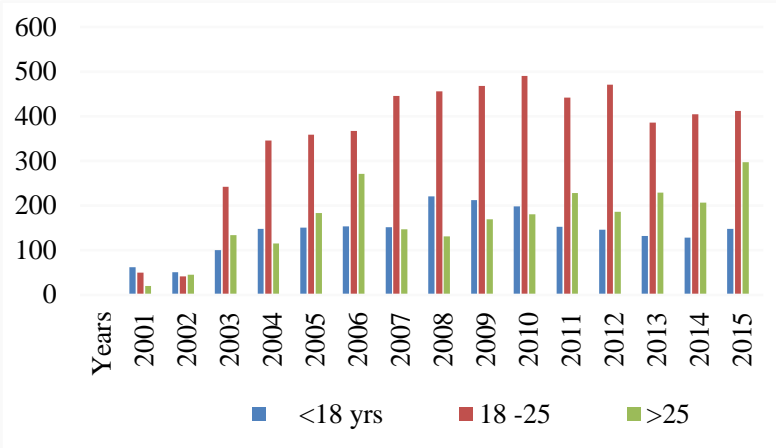

Figure 2: Distribution according to age of initiation of sexual activity.

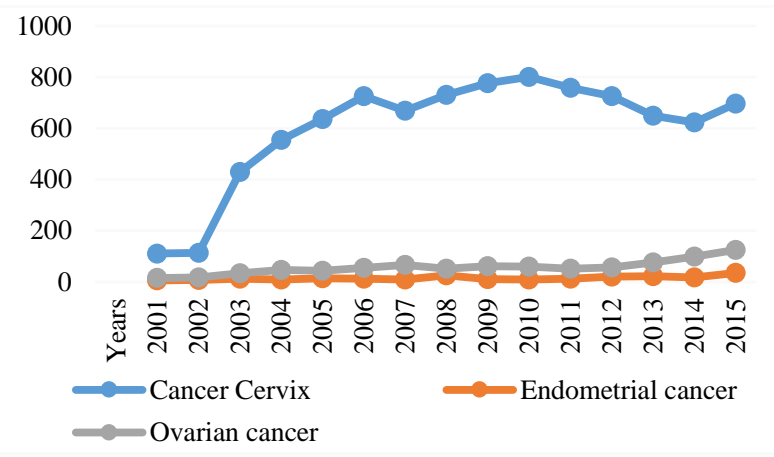

Figure 3: Distribution according to type of genital cancer.

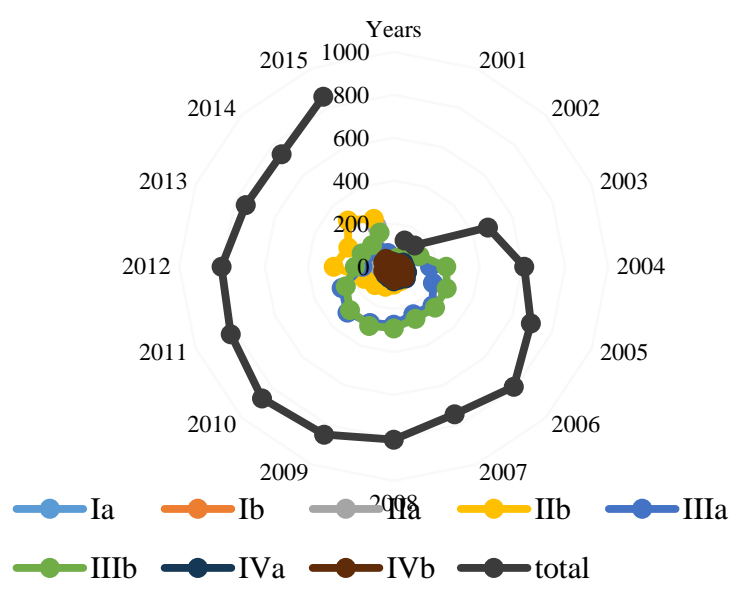

Figure 4: Distribution according to stage at the time of reporting.

Study of age at marriage showed that 15 years back in $2000,46.97 \%$ women gave history of early initiation of sexual activity as married at less than 18 years of age. With implementation of government policy of age at marriage should be 18 years or more, there is a shift showing that $48.07 \%$ women in 2015 gave history of 
marriage at age 18-25yrs (Figure 2). Still there was history of early exposure of sexual activity, acceptation to multiple partners or live in situations leading to overall increase to high risk behaviour.

On recording the parity of women we observed that $46.97 \%$ women in year 2000 had >6 children. Increasing awareness of family planning was reflected as slight shift showing $52.02 \%$ families with 3-6 children (Table 1).

Observation of contribution of cancer cervix, cancer endometrium and ovarian cancer to genital cancer revealed that cancer cervix was contributing to more than $90 \%$ than the others type of genital cancers. Over the time span of fifteen years there was about $11 \%$ reduction in cases of cancer cervix. It was significantly reduced over the last four- five years. Same time on the other hand there was an increase in prevalence of cancer endometrium and cancer ovary over last three years from $2.62 \%$ to $4.08 \%$ and from $10.17 \%$ to $14.59 \%$ respectively (figures 3).

Analysis of stage of cancer at the time of reporting showed that a decade and half ago nearly $44 \%$ women reported in stage III or more and this continued for a decade. Only in recent few years, there is shift to diagnosis of cancer in earlier stage i.e. stage II but still in a stage where surgical intervention cannot be offered (Figure 4).

Table 1: Distribution according to parity.

\begin{tabular}{|c|c|c|c|c|c|c|c|}
\hline \multirow{2}{*}{ Years } & \multicolumn{2}{|c|}{ <3 Children } & \multicolumn{2}{|c|}{ 3-6 Children } & \multicolumn{2}{|c|}{$>6$ Children } & \multirow[t]{2}{*}{ Total } \\
\hline & $\mathbf{N}$ & $\%$ & $\mathbf{N}$ & $\%$ & $\mathbf{N}$ & $\%$ & \\
\hline 2001 & 21 & $15.91 \%$ & 49 & $37.12 \%$ & 62 & $46.97 \%$ & 132 \\
\hline 2002 & 28 & $20.29 \%$ & 42 & $30.44 \%$ & 68 & $49.27 \%$ & 138 \\
\hline 2003 & 54 & $11.34 \%$ & 126 & $26.47 \%$ & 296 & $62.18 \%$ & 476 \\
\hline 2004 & 98 & $14.14 \%$ & 118 & $19.38 \%$ & 393 & $64.53 \%$ & 609 \\
\hline 2005 & 112 & $16.16 \%$ & 223 & $32.18 \%$ & 358 & $51.66 \%$ & 693 \\
\hline 2006 & 151 & $19.06 \%$ & 258 & $32.57 \%$ & 383 & $48.36 \%$ & 792 \\
\hline 2007 & 135 & $18.12 \%$ & 287 & $38.52 \%$ & 323 & $43.36 \%$ & 745 \\
\hline 2008 & 145 & $17.95 \%$ & 323 & $39.97 \%$ & 340 & $42.08 \%$ & 808 \\
\hline 2009 & 156 & $18.37 \%$ & 331 & $38.99 \%$ & 362 & $42.64 \%$ & 849 \\
\hline 2010 & 181 & $20.83 \%$ & 384 & $44.19 \%$ & 304 & $34.98 \%$ & 869 \\
\hline 2011 & 196 & $23.81 \%$ & 341 & $41.43 \%$ & 286 & $34.76 \%$ & 823 \\
\hline 2012 & 146 & $18.18 \%$ & 380 & $47.32 \%$ & 277 & $34.50 \%$ & 803 \\
\hline 2013 & 132 & $17.67 \%$ & 383 & $51.27 \%$ & 232 & $31.06 \%$ & 747 \\
\hline 2014 & 158 & $21.35 \%$ & 401 & $54.19 \%$ & 181 & $24.46 \%$ & 740 \\
\hline 2015 & 162 & $18.90 \%$ & 446 & $52.05 \%$ & 249 & $29.05 \%$ & 857 \\
\hline
\end{tabular}

\section{DISCUSSION}

The incidence of genital cancer at our Institute increased from $27.22 \%$ in 2001to $36.25 \%$ in 2015. Projections based on GLOBOCON 2012 predicted a significant increase of 19.3 million new cancer cases per year by 2025 due to growth and aging of global population. They also stated that more than half of all cancer and deaths due to cancer in 2012 occurred in developing regions. ${ }^{1,4-6}$

Many Indian studies supported the fact that most of women with genital cancer were from rural areas as majority of our population resides in villages. ${ }^{7,6}$ However there was a study conducted in rural Delhi which reported that the incidence of cancer in rural area was less compared to urban Delhi, India. They also emphasized that rural population was less than that of urban and was more educated compared to rest of rural India. $^{8}$

In present study we found that the $85 \%$ women from rural areas $75 \%$ were educated up to middle school and $76 \%$ belong to low socioeconomic strata. These women were unaware of sign and symptoms of genital cancers and thus there was delay in seeking treatment. Other Indian studies also came out with the fact that education, socioeconomic status and cultural beliefs were variables which influenced the women from reaching the health care facilities. ${ }^{9-12}$ This disparity was not limited to developing countries only but also seen in developed country. ${ }^{13,14}$

We observed that maximum incidence of genital cancer fall in women in 45-60 years age group (Figure 1). Recent studies in India reveal that age specific incidence reach a peak between 55 and 64 years. The mean age at 
diagnosis is 47 years in west and around the mid-forties in India. ${ }^{7,15,16}$ We observed that in year 2008 there was decreased incidence of genital cancer by almost $50 \%$ in 15-45 years age group at that period of time there was increased cases of hysterectomy reported in our state at young age group for precancerous lesions.

In present study we noticed that over the span of fifteen years there was shift of age of marriage from less than 18 years $46.97 \%$ to 18 -25years $48.07 \%$ (Figure 2). Still most of the women gave history of early initiation of sexual activity and multiple partners in lieu of migration, separation and second or third marriages. This behaviour was more prevalent in low socioeconomic strata. A study conducted in Maharashtra, India also reported that highrisk HPV was associated with increasing age, low education level, labour class, early age at first sexual intercourse, and widowhood or separation. ${ }^{18}$ All sexually active women are infected with HPV at least once anytime during their lifetime, and the highest prevalence is seen soon after the onset of sexual activities. ${ }^{19,20}$ About $50 \%$ of men and women would acquire genital HPV infection during their lifetime. ${ }^{20}$ Other studies also stated that the major risk factor for HPV infection is sexual behaviour, including early age of onset of sexual activity, multiple sexual partners, and co infection with HIV. ${ }^{21-23}$

In present study the parity of women with genital cancer exhibited a shift from $46.97 \%$ incidence of $>6$ children in year 2000 to $52.02 \%$ families with parity of 3-6 children. A large population based South Indian study reported that there is 2.5 times increased risk associated with increase in parity and age. ${ }^{24}$ Another study recorded increase in invasive cytopathological abnormalities with increasing age and parity. ${ }^{25}$ The risk of HPV infection in eastern India was found to be higher in married women and in women with parity $>4$.

The cancer cervix was the major contributor of genital cancer. It is the second most common cancer in women aged 15-44 years. India also has the highest age standardized incidence of cervical cancer in South Asia at 22, compared to 19.2 in Bangladesh, 13 in Sri Lanka, and 2.8 in Iran. ${ }^{26}$ Over last 15 years there was decline in cases of cancer cervix by $11 \%$ at our centre. Similar tends were reported by the Bangalore registry, India, the age-adjusted rate fell from 32.4 in 1982 to 18.7 in 2009, in Barshi from 22.1 in 1988 to 14.1 in 2010, in Chennai from 41 to 16.7 in 2009, and in Thiruvananthapuram from 9.2 in 2005 to 7.7 in $2011 . .^{15}$ The annual percentage decrease ranged from a minimum of $1.3 \%$ in Bhopal to $3.5 \%$ in Chennai in the years from 1982 to $2010 .{ }^{27}$ Over a 30 -year study period in the Mumbai registry there was an estimated annual percent change in cervical cancer by $1.8 \% .{ }^{28}$ On the other hand, in Odisha, India cancer cervix was the second most common cancer, reported an increase of $3.1 \%$ from 2001 to $2011 .^{29}$
For ovarian cancer, the trends vary according to geographic region- with decreasing rates in the United States and Northern Europe but increasing rates in a few Southern and Eastern European countries and in Asian countries including Japan, China and Hong Kong. ${ }^{30-33}$ Similarly we observed an increase in the incidence of ovarian and endometrial cancer in recent years. Takiar et al reported from pooled data of five major cities that the second contributor was cancer ovary, fourth was cancer endometrium followed by cancer cervix. They reported cancer corpus uteri as the new emerging site for cancer in many cities of India. We attribute this increase to sedentary lifestyle, increased incidence of obesity and metabolic syndromes.

The women with genital cancer in our study when reported for the first time, about half of them were found to be in advanced stage (Figure 4). A south Indian study reported that $92.94 \%$ women when diagnosed were in stage III and IV. ${ }^{17}$ Approximately $70 \%$ women with ovarian cancers were diagnosed at advanced stage disease which is associated with poorer prognosis. ${ }^{34}$ endometrial cancer when diagnosed at local or regional stage the five year survival is $96 \%$ and $76 \%$ respectively. While distant stage survival decreases to $16 \% .^{13,35,36}$

\section{CONCLUSION}

The increasing incidence of cancer in India has mirrored trends in developed countries. Over the last two decades, the urbanization and increasing modernization of India has transformed education, lifestyle, health-care access and longevity, and has contributed to an increased risk profile for chronic diseases such as cancer. In India, high incidence rates were reported for cancer cervix, and ovary; which together accounted for almost $59 \%$ of all cancers in women.

The most significant changing trend in our study was that cancer cervix has decreased by $11 \%$. Another positive trend found in our study was a shift from stage III to stage II at the time of reporting. However, it is unfortunate that cancer endometrium is increasing. It could be related to an increase in PCOD, diabetes and metabolic syndrome.

The positive trends seem like a new beginning and every gynaecologist should contribute to further reduce the incidence.

\section{ACKNOWLEDGEMENTS}

The authors are thankful to all the faculty and technical staff of department of Obstetrics and Gynaecology, Dr. BRAM Hospital, Pandit Jawahar Lal Nehru Memorial Medical College, Raipur, Chhattisgarh, India, for their cooperation and support during the entire study period. Authors acknowledge the immense help received from the scholars whose articles are cited and included in references of this manuscript. The authors are also 
grateful to authors/editors/publishers of all those articles, journals and books from where the literature for this article has been reviewed and discussed.

Funding: No funding sources

Conflict of interest: None declared

Ethical approval: The study was approved by the Institutional Ethics Committee

\section{REFERENCES}

1. Jemal A, Center MM, DeSantis C, Ward EM. Global patterns of cancer incidence and mortality rates and trends. Cancer Epidemiol Biomarkers Prev. 2010;19(8):1893-907.

2. Country Statistics and global health estimates by WHO and UN partners, January 2015. Available from http://who.int/gho/mortality burden disease/en/

3. Ferlay J, Soerjomataram I, Ervik M, Dikshit R, Eser S, Mathers C, et al. Cancer Incidence and Mortality Worldwide: IARC Cancer Base No. 11 GLOBOCAN 2012 v1.0, Lyon, France: International Agency for Research on Cancer. 2013.

4. Bleyer A, Barr R, Hayes-Lattin B, Thomas D, Ellis C, Anderson B. Biolog and clinical trials subgroups of the US national cancer institute progress review group in adolescent and young adult oncology. The distinctive biology of cancer in adolescents and young adults. Nat Rev Cancer. 2008;8:288-98.

5. Takiar R, Nadayil D, Nandakumar A. Projections of number of cancer cases in India (2010-2020) by Cancer Groups Asian Pacific J Cancer

6. Ali I, Wani WA, Kishwar S. Cancer scenario in India with future perspectives, Cancer Therapy. 2011; 8:56-70.

7. Nandakumar A, Ramnath T, Chaturvedi M. The magnitude of cancer cervix in India. Indian J Med Res. 2009;130(3):219-21

8. Tyagi MN, Raina V BB. Cancer incidence in rural Delhi 2004-05; Asian Pacific J Cancer Prev. 2010;11:73-7.

9. Aswathy S, Javed R, Dinesh A. Epidemiology of cervical cancer with special focus on India. Int $\mathrm{J}$ Wom Health. 2015;7:405-14.

10. Dutta S, Biswas N, Mukheriee G. Evaluation of socio demographic factors for non-compliance to treatment in locally advanced cases of cancer cervix in a rural medical college hospital in India. Indian J Palliat Care. 2013;19(3):158-65.

11. Tripathi N, Yugantara KR, Dhobale RV, Gore AD. Barriers for early detection of cancer amongst Indian rural women. South Asian J Cancer. 2014;3(2):122-8.

12. Puri S, Ashat M, Pandey A, Goel NK, Singh A, Kaushal V. Socio-demographic characteristics of cancer patients: Hospital based cancer registry in a tertiary care hospital of India. Indian $\mathrm{J}$ Cancer. 2014;51:1-4.

13. Collins Y, Holcomb K, Chapman-Davis E, Khabele D, FarleyJohn H. Gynecologic cancer disparities: A report from the health disparities task force of the society of gynecologic oncology. Gynecologic Oncol. 2014;133:353-61.

14. Albano JD, Ward E, Ahmedin J, Anderson R, Cokkinides VE, Murray T, et al. Cancer mortality in the united states by education level and race. J Nat Cancer Inst. 2007;99:1384-94

15. National Center for Disease Informatics Research, National Cancer Registry Programme. ICMR three year report of population based registries, 20092011, Bangalore, India: NCDIR-NCRP (ICMR): 2014

16. Sreedevi A, Javed R, Dinesh A. Epidemiology of cervical cancer with special focus on India. Int $\mathrm{J}$ Womens Health. 2015;7:405-14.

17. Mahadevappa1 K, Prasanna N, Bembalgi S, Murugendrayya CS, Downstaging of carcinoma cervix: yet to reach the unreached. Int $\mathrm{J}$ Reprod Contracept Obstet Gynecol. 2016;5(2):349-53.

18. Sauvaget C, Nene B, Jayant K. Prevalence and determinants of high-risk human papillomavirus infection in middle-aged Indian women. Sex Transm Dis. 2011;38(10):902-6.

19. Brown DR, Shew ML, Qadari B. A longitudinal study of genital pappilomavirus infection in a cohort of closely followed adolescent women. J Infect Dis. 2006;191:182-92.

20. Department of Health and Human Services. Centers for disease control and prevention. Genital HPV infection fact sheet; 2004. Available from: http://www.cdc.gov/std/hpv/stdfact-hpv.htm

21. IARC monographs on the evaluation of carcinogenic risks to humans. Human Papilloma Viruses. Volume 90. Lyon: International agency for research on cancer; 2006.

22. International collaboration of epidemiological studies of cervical cancer. Cervical carcinoma and sexual behavior: collaborative reanalysis of individual data on 15,461 women with cervical carcinoma and 29,164 women without cervical carcinoma from 21epidemiological studies. Cancer Epidemiol Biomarkers Prev. 2009;18:1060-9.

23. Goodarz D, Vander HS, Lopez AD, Murray CJL, Majid E, and the comparative risk assessment collaborating group (Cancers). Causes of cancer in the world: comparative risk assessment of nine behavioral and environmental risk factors. Lancet. 2005;366:1784-93.

24. Jiss VT, Nea M, Matti H. Sociodemograhic and reproductive risk factors for cervical cancer-a large prospective cohort study from Rural India. Asian Pac J Cancer Prev. 2012;13:2991-5.

25. Misra JS, Srivastava S, Singh U. Risk-factors and strategies for control of carcinoma cervix in India: hospital based cytological screening experience of 35 years. Indian J Cancer. 2009;46(2):155-9.

26. ICO Information Centre on HPV and cancer. Human Papillomavirus and Related Diseases in India (Summary Report 2014-08-22); 2014 
27. National Centre for Disease Informatics and Research, National Cancer Registry Programme, ICMR. Time trends in cancer incidence rates, 19822010. Bangalore, India: NCDIR-NCRP (ICMR); 2013.

28. Dhillon PK, Yeole BB, Dikshit R. Trends in breast, ovarian and cervical cancer incidence in Mumbai, India over a 30-year period, 1976-2005: an ageperiod-cohort analysis. $\mathrm{Br} \mathrm{J}$ Cancer. 2011;105(5):723-30.

29. Hussain MA, Pati S, Swain S. Pattern and trends of cancer in Odisha, India: a retrospective study. Asian Pac J Cancer Prev. 2012;13(12):6333-6.

30. Takiar Ramnath, Vijay CR. An alternative approach to study the changes in the cancer pattern of women in India (1988-2005). Asian Pac J of Cancer Prev. 2010;11:1253-6.

31. Kjaerbye-Thygesen A, Huusom LD, Frederiksen K, Kjaer SK, Trends in the incidence and mortality of ovarian cancer in Denmark 1978-2002. Comparison with other Nordic countries. Acta Obstet Gynecol Scand. 2005;84:1006-12.

32. Morris CR, Rodriguez AO, Epstein J, Cress RD, Declining trends of epithelial ovarian cancer in California. Gynecol Oncol. 2008;108:207-13.
33. Marugame T, Hirabayashi $\mathrm{Y}$,Comparison of time trends in ovary cancer incidence (1973-1997) in East Asia, Europe, and the USA, from cancer incidence in five continents. Japan J Clin Oncol. 2007;37:802-3.

34. Song F, He M, Li H, Qian B, Wei Q, Zhang W, et al. A cancer incidence survey in Tianjin: the third largest city in China between1981 and 2000. Cancer Causes Control. 2008;19:443-50.

35. Howlader N, Noone AM, Krapcho M, Neyman NN, Aminou R, Altekruse SF. SEER Cancer Statistics Review, 1975-2009. (Vintage 2009 Populations). Bethesda, MD: National Cancer Institute. April 2012. Available from http:// seer.cancer.gov/ csr/1975_2009_pops09/, based on November 2011 SEER data submission, posted to the SEER web site.

36. Phyu AS, Mark E, Vladimir S. Comparison of cancer survival in New Zealand and Australia, 20062010. NZMJ. 2014;127(1407):1-13.

Cite this article as: Singh A, Kujur A. Changing trends in genital cancer. Int J Reprod Contracept Obstet Gynecol 2017;6:850-5. 